\title{
PSICOMOTRICIDADE NOS ANOS INICIAIS DO ENSINO FUNDAMENTAL
}

\section{PSYCHOMOTRICITY IN THE EARLY YEARS OF ELEMENTARY SCHOOL}

\author{
Flaviane Pereira da Silva ${ }^{1}$ \\ Nayara Ferreira dos Santos ${ }^{2}$ \\ Maria Ângela de Moraes Cardoso ${ }^{3}$ \\ https://doi.org/10.29327/216986.1.1-5
}

RESUMO: O presente estudo foi um tema escolhido a partir da realização de um estágio supervisionado, onde se percebeu a relevância da psicomotricidade para a formação do aluno. Diante disso, teve o objetivo geral de: analisar a importância de se trabalhar a psicomotricidade nos anos iniciais do ensino fundamental. Seus objetivos específicos buscaram: compreender o conceito de psicomotricidade; identificar os elementos básicos da psicomotricidade e apontar as contribuições da psicomotricidade para o desenvolvimento da criança. Trata-se de uma pesquisa bibliográfica, com embasamento teórico para responder a questão norteadora: "quais as contribuições da psicomotricidade nos anos iniciais?" Por acreditar na importância da psicomotricidade para o desenvolvimento humano, devendo então estar presente no ambiente escolar garantindo a aprendizagem integral do sujeito.

Palavras-chave: Psicomotricidade. Anos iniciais. Desenvolvimento. Aprendizagem.

\footnotetext{
1 Licenciada do curso de Pedagogia EAD da Faculdade do Noroeste de Minas - FINOM. E-mail: flaviane@joparseguros.com.br

2 Licenciada do curso de Pedagogia EAD da Faculdade do Noroeste de Minas - FINOM. E-mail: nayara.santos@soufinom.com.br

${ }^{3}$ Mestre em Educação pela UCB. Diretora Acadêmica da Faculdade Tecsoma. E-mail: direcaoacademica@tecsoma.br
} Educação In Loco, v.01, n. 01, jan.-jun. 2020 - ISSN 2675-4304 
ABSTRACT: The present study was a theme chosen from the accomplishment of a supervised internship, where it was realized the relevance of psychomotricity for the student formation. Given this, it had the general objective of: analyzing the importance of working on psychomotricity in the early years of elementary school. Its specific objectives sought: to understand the concept of psychomotricity; identify the basic elements of psychomotor skills and point out the contributions of psychomotor skills to child development. This is a bibliographical research, with theoretical basis to answer the guiding question: "what are the contributions of psychomotricity in the early years?" Believing in the importance of psychomotricity for human development, should be present in the school environment ensuring integral learning of the subject.

Keywords:Psychomotricity. Early years. Development. Learning.

\section{Introdução}

A presente pesquisa teve como objetivo geral analisar a importância do trabalho com a psicomotricidade nos anos iniciais do ensino fundamental. Partiu-se do conceito de psicomotricidade; buscou identificar os seus elementos básicos e apontar as suas contribuições para o desenvolvimento da criança.

A escolha do tema aconteceu por meio da realização de um estágio supervisionado, onde foi percebido que o projeto político da escola enfatizava observar os movimentos da criança para trabalhar seu desenvolvimento mental e físico. Através do estágio supervisionado notou-se a importância de analisar as questões psicomotoras nos anos iniciais do ensino fundamental.

Ressalta-se que a psicomotricidade promove o desenvolvimento da criança, sobretudo em relação ao acompanhamento suas habilidades dentro e fora da escola, 
principalmente suas experiências vivenciadas em espaços informais, fatores que relaciona a criança com o meio que vive.

Trata-se de uma pesquisa bibliográfica, analisando livros, artigos, entre outros documentos com embasamento teórico, a fim de se atingir os objetivos propostos e responder à problemática: "quais as contribuições da psicomotricidade nos anos iniciais?". Acreditando, nesse sentido que a psicomotricidade é indispensável para o desenvolvimento integral do sujeito.

\section{Psicomotricidade e seus elementos básicos}

De acordo com Fonseca (1988), do grego psyqué: alma/mente e do verbo latino moto: mover-se consequentemente, sendo este conjunto de palavras, originou-se a palavra psicomotricidade que está ligada ao movimento corporal e ao qual ação se quer alcançar. É uma base para a aprendizagem das crianças, além de formar a motricidade, afetividade e o psicológico.

Segundo Ferronatto (2006), o termo psicomotricidade surgiu com a necessidade de encontrar uma área que tivesse respostas para fenômenos clínicos. Esse termo está relacionado à capacidade do sujeito de realizar movimentos, bem como o próprio desenvolvimento do corpo. É a ciência que estuda o homem através do seu corpo, em movimento e,

[...] em relação ao seu mundo interno e externo, bem como suas possibilidades de perceber, atuar, agir com o outro, com os objetos e consigo mesmo. Está relacionada ao processo de maturação em que o corpo é a origem das aquisições cognitivas, afetivas e orgânicas e é movimentada por três aspectos básicos: o movimento, o intelecto e o afeto (OLIVEIRA, 2005, p. 96).

Nesse sentido, é fundamental favorecer possibilidades intencionais para que as crianças se desenvolvam em todos os sentidos. De acordo com Fonseca (1995), psicomotricidade é a ciência que estuda o processo de maturação, enxergando o corpo como a fonte das aquisições orgânicas, afetivas e cognitivas, que 
estão relacionados com o movimento, que são conhecimentos básicos para essas aquisições.

Para Fonseca (1995) a psicomotricidade é a a integração superior da motricidade, ou seja, está entre a criança e o meio como instrumento privilegiado que permite que a consciência se materialize. É, sobretudo, capaz de oferecer à criança estímulos de tomada de consciência sobre o seu corpo, em relação aos outros e ao ambiente que o cerca.

A Psicomotricidade é muito importante para o desenvolvimento da criança, uma vez que verifica as habilidades, o relacionamento afetivo com o meio, a formulação de estratégias, a formulação de estruturas mentais, condições de realizar múltiplo movimentos, além de auxiliar no desenvolvimento da leitura e escrita (FERRONATTO, 2006, p. 86).

A psicomotricidade auxilia no desenvolvimento: "motor e intelectual da criança, por isso, fazem-se necessário sempre estudar e conhecer os conceitos e pesquisas na área de psicomotricidade" (CASTILHO-WEINERT, 2011, p. 78). São elementos básicos da psicomotricidade: motricidade fina; motricidade global; equilíbrio; esquema corporal; organização espacial; organização temporal e a lateralidade.

Ressalta-se que:

Seja qual for à experiência proposta e o método adotado, o educador deverá levar em consideração as funções psicomotoras (esquema corporal, lateralidade, equilíbrio, etc.) que pretende reforçar nas crianças com as quais está trabalhando. Mesmo levando em conta que, em qualquer exercício ou atividade proposta, uma função psicomotora sempre se encontra associada a outras, o professor deverá estar consciente do que exatamente está almejando e onde pretende chegar (NEGRINE, 1995, p.25).

De acordo com Rosa Neto (2002), a motricidade fina é uma habilidade para realizar movimentos pequenos, com grande 
precisão e utilizando pouca força. Trabalha as articulações em movimentos dos ombros para as pontas dos dedos, caracteriza-se em uma atividade preparatória para a escrita.

A motricidade global, segundo a autora são habilidades motoras que não levam em conta a precisão do movimento, por ser um resultado de ações de um conjunto de músculos que trabalham juntos. Ajuda diretamente no equilíbrio postural, na realização de movimentos combinados.

O equilíbrio é o principal segmento da motricidade, conforme Rosa Neto (2002), o equilíbrio é o estado de um corpo quando as suas forças atuam e se anulam, quando a pessoa passa a controlar seu tônus postural, respiração e gestos para controlar seus movimentos e suas respostas musculares.

O esquema corporal é de extrema importância na área da educação, pois com o desenvolvimento deste a criança verifica a organização de si mesmo como um ponto de partida das diversas possibilidades para agir. É quando a criança toma consciência do seu próprio corpo.

A organização espacial, por sua vez, é uma construção e elaboração mental que se opera: "através dos movimentos em relação aos objetos do meio. Através de um trabalho mental, selecionamos, comparamos os objetos, agrupamos, extraímos e classificamos" (FERRONATTO, 2006 p. 88). Já a organização temporal inclui:

A lateralidade é a dominância de um dos lados do corpo. Segundo Rosa Neto (2002), é a preferência da utilização de uma dessas partes, o que leva a aprendizagens que dará suporte a intencionalidade ao longo da vida da criança quando se deparar com o seu meio. Pode-se entender que a psicomotricidade auxilia a criança a se descobrir através de experiências corporais, motoras e afetivas, aumentam as condições básicas para as aprendizagens escolares.

De acordo com Fonseca (1995), foi a partir dos estudos de Wallon que a psicomotricidade adquiriu importância na aprendizagem. Nesse sentido, cabe salientar a relevância desta ser 
trabalhada no ambiente escolar, onde os sujeitos passam anos de sua vida para aprender.

Segundo Olvieira (2005), o desenvolvimento motor da criança é determinado, em sua maioria pelo biológico e pelo meio social. Diante disso, pode-se destacar que a escola é o melhor lugar para a criança desenvolver sua parte motora, porque o ser humano é sujeito social e, através das interações e das relações com os demais sujeitos, ele aprende.

Libâneo (1994) destaca que as pessoas estão sempre aprendendo. A escola é diante disso, um ambiente de construção de aprendizagens. Dessa forma, Lopes (1996) ressalta que o processo ensino-aprendizagem se constitui numa dinâmica dentro da sala de aula, ou seja, existe a presença de dois tipos de sujeito, um que ensina e outro que aprende.

A educação psicomotora concerne uma formação de base indispensável a toda criança que seja normal ou com problema. Responde a uma dupla finalidade: assegurar o desenvolvimento funcional tendo em conta possibilidade da criança e ajudar sua afetividade a expandir-se através do intercâmbio com ambiente humano (LE BOUCH, 1992 p. 15).

Assim sendo, a escola, nesse sentido é um espaço onde acontecem as relações interpessoais e institucionais capaz de instruir e formar. Segundo Hora (1994) a escola contribui significativamente para o desenvolvimento do sujeito, podendo favorecer a ampliação e a compreensão de si mesmo, dos outros, do mundo e das relações sociais, que são essenciais para o seu desenvolvimento.

\section{Escola como espaço de desenvolvimento e formação}

Canário (2002), afirma que a e que escola é uma instituição com valores diversificados, que se torna uma "fábrica de cidadãos." A escola na formação de cidadãos, seleciona os saberes dos alunos para adequá-los aos saberes da escola, construindo dessa forma ações educativas. 
Araújo (2003), a escola é um espaço onde acontecem as relações interpessoais e institucionais capazes de agregar laços de comunidade, ou até mesmo de parentesco, sendo responsável por instruir e formar.Deve propiciar condições de interações entre professores e alunos, com o objetivo de apropriar o conhecimento.

Estas considerações, em conjunto, têm sérias implicações para a Educação: procede-se na aprendizagem, do social para o individual, através de sucessivos estágios de internalizarão, com auxílio de adultos ou de companheiros mais experientes (DAVIS; OLIVEIRA, 1994, p.22).

Nesse sentido, Libâneo (2001) destaca que os objetivos da escola é preparar o sujeito para a sociedade, integrando-o ao mundo do trabalho de forma a promover sua formação sociocultural. O sujeito deve ser capaz de exercer a cidadania, conhecendo os seus direitos e deveres, bem como respeitando a individualidade dos demais sujeitos sociais.

Segundo Freire (2001) é de suma importância para a formação crítica do estudante, que haja uma seleção de conteúdo. Ele destaca que essa articulação precisa garantir a unificação dos conhecimentos escolares e com a realidade dos alunos, permitindo estes se identifiquem agentes que podem agir e transformar a realidade que o cerca. A escola amplia o mundo dos alunos,

[...] convidando-os a olhar suas experiências com um outro lente êxito com uma lente, que não a seja familiar, o que alterará os significados já conhecidos. A escola [...] tem a responsabilidade da apresentação de conceitos e conteúdos herdados de nossa cultura, pois muitas crianças só terão acesso a esta herança, através de sua passagem pela escola, que deve então, abrir caminhos de acesso à cultura de maneira igualitária para todos [...] (CASTRO, 2003, p.1).

Assim entende-se que a escola é um espaço de diversidade cultural, um ambiente de diálogo, encontros e confrontos, justamente por essa pluralidade de valores, crenças, linguagens, hábitos e 
costumes. Portanto, precisa também privilegiar a democracia contribuindo para a construção de conhecimento e cidadania.

A escola é um organismo vivo e bastante dinâmico, sendo entendida como unidade social. Diante disso, caracteriza-se por uma rede de relações entre aqueles que a compõe, interferindo de forma direta ou indireta em sua organização. Surge a partir disso a necessidade da gestão escolar.

Martins (2004), afirma nesse sentido, que o sistema educacional é capaz de trazer felicidade e triunfo ao indivíduo, tendo o reconhecimento de que por meio da educação como direito, o homem tornava-se satisfeito, sente-me melhor, feliz, sendo um sujeito emancipado e livre.

A escola é uma organização que ajuda a construir valores, contribui para a formação dos sujeitos que ali estão:

[...] mediante experiências de aprendizagem e ambiente educacional condizentes com os fundamentos, princípios e objetivos da educação. $\mathrm{O}$ seu ambiente é considerado de vital importância para o desenvolvimento de aprendizagens significativas que possibilitem aos alunos conhecerem o mundo e conhecerem-se no mundo, como condição para o desenvolvimento de sua capacidade de atuação cidadã (LÜCK, 2009, p.20).

O ser humano é sujeito social e, através das interações e das relações com os demais sujeitos, ele aprende. Libâneo (1994) destaca que as pessoas estão sempre aprendendo. A escola é diante disso, um ambiente de construção de aprendizagens. Dessa forma, Lopes (1996, p. 107) ressalta que o processo ensino-aprendizagem se constitui numa dinâmica dentro da sala de aula, ou seja, existe a presença de dois tipos de sujeito, um que ensina e outro que aprende.

Assim, a aprendizagem vai acontecer também na prática com a intervenção e auxílio dos educadores presentes no ambiente escolar. No entanto, para que a aprendizagem se efetive, é preciso entender que $o$ ato de ensinar busca alcançar a aprendizagem do estudante por meio do conteúdo e, para que esse conteúdo seja aprendido, o aluno deve ser motivado a aprender. 
Para ser considerada pública, a participação deve acontecer dentro da escola, por parte do gestor, dos pais, alunos, professores e demais funcionários. Nesse sentido, entende-se que a democratização:

[...] começa no interior da escola, por meio da criação de espaços nos quais professores, funcionários, alunos, pais de alunos etc. possam discutir criticamente o cotidiano escolar. Nesse sentido, a função da escola é formar indivíduos críticos, criativos e participativos (OLIVEIRA, et al. 2012, p. 10).

A escola ao conquistar sua autonomia se fortalece, promovendo a qualidade na educação, constituindo-se num instrumento de construção para a cidadania. Dessa forma, a democratização torna-se uma perspectiva pedagógica, que pode ser alcançada através da prática social para então fortalecer o processo democrático.

Para Masetto (1994), a aprendizagem é pessoal e, no processo de ensino aprendizagem, o aluno é o sujeito e construtor desse processo. Nessa perspectiva a escola buscando uma formação e um desenvolvimento integral da criança deve contar com a organização do tempo e espaço para ser efetivado para propiciar a aprendizagem.

Para a realização de atividades psicomotora o espaço físico é fundamental ser pensado, por ser o lugar onde se permite desenvolver múltiplas habilidades e sensações, por meio da diversidade, ele desafia aqueles que o ocupam. Segundo Barbosa (2006), esse desafio constrói-se pelos símbolos e pelas linguagens que o transformam e o recriam continuamente.

Ainda nesse sentido, Silva (2010) completa que o tempo e o espaço na instituição de ensino devem ser aliados ao trabalho escolar, para tanto o planejamento é fundamental para que todo o tempo e espaço sejam bem utilizados, com atividades diversificadas e intencionadas a fim de obter aprendizagens significativas.

Portanto, destaca-se o espaço e o tempo na escola como elementos básicos e constitutivos da atividade educativa, assim a vivência no espaço é capaz de transformá-lo em um lugar de 
conhecimento, sendo a escola um lugar por ser um espaço ocupado e utilizado. Vinão Frago (1998), afirma nessa perspectiva que se deve privilegiar a cidadania no espaço escolar, a solidariedade e o diálogo para reestruturar as salas de aulas, bem como promover atividades de psicomotricidade para o desenvolvimento da criança.

\section{Contribuições da psicomotricidade para o desenvolvimento da criança}

O ensino e a aprendizagem são compreendidos como parte de uma dinâmica que acontece dentro da sala de aula e são vários os fatores responsáveis por esse processo educativo. Como destaca Lopes (1996), a aprendizagem escolar envolve vários fatores afetivos e sociais.

Diante dessa afirmativa, a aprendizagem envolve também as condições de vida do educando, a sua relação com a escola, sua percepção e compreensão do conhecimento, o que possibilita a compreensão de que o ensino é o processo em que o professor planeja um objetivo e o coloca em prática através de atividades para que $o$ aluno chegue a uma aprendizagem.

Ações psicomotoras, segundo Molinari e Sens (2003), se diversificam em função das relações morais, sociais e das capacidades e maneira de ser de cada um, considerando os seus valores. É, sobretudo, um fenômeno natural que favorece determinados comportamentos, propiciando transformações.

Aspectos como: motores, sociais e afetivos são algumas das contribuições da psicomotricidade para o desenvolvimento humano. $\mathrm{Na}$ participação das atividades, Kishimoto (2010), destaca que as crianças compreendem e se expressam por meio de diversas linguagens.

Além do prazer, atividades diversificadas facilitam a aprendizagem, ressaltam-se as brincadeiras, pois garantem o desenvolvimento pessoal, social e cultural, ajuda no processo de socialização, comunicação, expressão e construção do conhecimento. Nesse sentido, entende-se que: 
[...] as crianças evoluem por intermédio de suas próprias brincadeiras e das invenções de brincadeiras feitas por outras crianças e por adultos [...]. A brincadeira é a prova evidente e constante da capacidade criadora, que quer dizer vivência [...]. A brincadeira fornece uma organização para a iniciação de relações emocionais e assim propicia o desenvolvimento de contatos sociais (WINNICOTT, 1979, p. 163).

De acordo com a perspectiva sociocultural a característica social é primordial para o desenvolvimento infantil. Vygotsky (1994) destaca que atividades lúdicas são também psicomotoras e permitem que a criança descubra as relações existentes entre os homens. Conseguem avaliar suas habilidades e compará-las com as das outras crianças.

Essas atividades permitem que a criança se desenvolva individual ou socialmente. São atividades que devem ser direcionadas para atingir objetivos, mediadas pelo professor, sendo assim, o aluno aprende enquanto brinca, se diverte, seja sozinho, ou em grupo.

O trabalho com a psicomotricidade deve ser feito de forma que a criança se desenvolva da melhor maneira possível, se preparando para a vida. Fonseca (1988) salienta que pela motricidade a inteligência é materializada, uma vez que imagens são elaboradas e a partir disso, se constroem as representações. Assim, a psicomotricidade proporciona condições necessárias para que as crianças tenham um bom desempenho escolar, utilizando o movimento para atingir outras aquisições como as intelectuais.

Ajuriaguerra (1980), afirma que pela motricidade e a visão a criança descobre o mundo a sua volta, manipulando objetos redescobre o mundo. Nesse sentido, cabe destacar que a aprendizagem da leitura e da escrita por ser um processo complexo envolve diversas habilidades e sistemas. Por isso, deve-se considerar que nos anos inicias, o comportamento motor deve estar presente na maioria das atividades de aprendizagem e de desenvolvimento.

A escrita é um meio de comunicação e expressão pessoal, que exige o desempenho sonoro e gráfico. A constituição do código 
gráfico e a sua decifração dependem da atuação de funções psicomotoras. Le Boulch (1987) afirma que quando ocorrem falhas no desenvolvimento motor, pode consequentemente ocorrer falhas na aquisição da linguagem verbal e escrita.

As contribuições da psicomotricidade são inúmeras durante o processo de alfabetização, com a lateralidade a criança já apresenta a sua dominância; nas habilidades conceituais, elas já tem conhecimento numérico; na área de coordenação manual e visual a criança consegue acompanhar as linhas do texto, folhear o caderno segurar o lápis de forma adequada.

$\mathrm{Na}$ percepção auditiva, a criança identifica os sons; na percepção visual, orientação espacial e habilidades conceituais e lateralidade, tem-se reconhecimento das dimensões do papel, orientase a leitura e a escrita da direita pra esquerda. Comunicação e expressão permite a pronúncia adequada das letras até as palavras, ou frases. Em orientação espacial, a criança sabe o que vem antes ou depois, que é conhecido como sucessão temporal.

Tisi (2004) ressalta que o corpo da criança, é um mundo de descobertas, de desafios e de construção. O professor como mediador pode ajudar a criança a realizar livremente suas experiências motoras. Nessa perspectiva Freire (1997) afirma que o corpo tem imensa capacidade de educar. Assim, na área da educação, a psicomotricidade estimula habilidades e aptidões e o desenvolvimento cognitivo, além de formar atitudes saudáveis nas ações das crianças.

No processo de ensino-aprendizagem, especificamente na alfabetização, a criança precisa saber usar os seus olhos para ler e as suas mãos para escrever. Para tanto, deve aprender a dominar os movimentos de forma adequada para que possa executar habilidades como essas. O docente além de alfabetizar, assume o papel de estimular funções psicomotoras para que aconteça o aprendizado formal, dosando teoria e prática conforme as necessidades dos seus educandos.

\section{Considerações Finais}

Educação In Loco, v.01, n. 01, jan.-jun. 2020 
Compreendendo a psicomotricidade como uma ciência que estuda o indivíduo através do seu corpo em movimento, relacionando-o ao seu ambiente interno e externo, destaca-se a psicomotricidade como uma ação de finalidade pedagógica e psicológica, extremamente importante para o desenvolvimento integral da criança.

A psicomotricidade busca fazer conexão nos aspectos cognitivos, emocionais e motores nas diversas etapas da vida do ser humano, sobretudo, na infância, por isso a necessidade de se trabalhar com atividades psicomotoras para que a criança tenha noção do seu corpo, do espaço e de como o ato de se mover pode ser determinante para o seu desenvolvimento.

Ela proporciona aos sujeitos condições mínimas e fundamentais para um bom desempenho escolar, por desenvolver todo o potencial da criança. Entende-se que para uma educação de qualidade, nutrir as exigências básicas da criança é fundamental, bem como permitir experiências diversificadas que facilitem o seu aprendizado e lhe proporcione uma preparação para a vida.

Neste aspecto, destaca-se que essa pesquisa foi relevante para o campo educacional, visto a importância do tema em destaque. Dessa forma pode-se dizer que a psicomotricidade é um fator essencial e indispensável para o desenvolvimento uniforme da criança. Portanto essa pesquisa não se finda, podendo ser objeto para futuras investigações.

\section{Referências bibliográficas}

AJURIAGUERRA, J. - Manual de psiquiatria infantil, 2 ed. São Paulo: Masson do Brasil, 1980.

ARAÚJO, Ulisses F. Temas transversais e a estratégia de projetos. São Paulo: Moderna, 2003.

BARBOSA, Maria Carmen Silveira. Por amor e por força: rotinas na educação Infantil. Porto Alegre: Artemed, 2006.

CASTILHO-WEINERT, Luciana Vieira; SANTOS, Elgison da Luz dos; BUENOMarcelo Rodrigues. Intervenção Fisioterapêutica Psicomotora em Crianças comAtraso noDesenvolvimento. 
Revista Brasileira de Terapia e Saúde, 1(2):75-81,Matinhos (PR) 2011.

Disponível em: $<$ http://omnipax.com.br/ojs/index.php/RBTS/article/view/10/17>. Acesso em: 30 deout. 2019.

CASTRO, Gilda de. Professor submisso, aluno-cliente: reflexões sobre a docência no Brasil. Rio de Janeiro: DP\&A, 2003.

DAVIS, C \& OLIVEIRA, Z. M. R. Psicologia na educação. $2^{\mathrm{a}}$ ed. São Paulo: Cortez, 1994.

FERRONATTO, Sônia Regina Brizolla, Psicomotricidade e Formação deProfessores: uma proposta de atuação. Dissertação (Mestrado) PUC-Campinas, Centro de Ciências Sociais Aplicadas, 2006.

FONSECA, Vítor da. Manual de Observação Psicomotora: significaçãopsiconeurológica dos fatores psicomotores. Porto Alegre: Artes Médicas, 371 p. 1995.

FONSECA, Vítor da. Psicomotricidade. $2^{\text {a }}$. ed.São Paulo:Martins Fontes, 1988.

FONSECA, J. J. S. Metodologia da pesquisa científica. Fortaleza: UEC, 2002.

FREIRE, Paulo. A Educação na Cidade. São Paulo: Cortez, 2001.

FREIRE, J. B. Educação de corpo inteiro: teoria e prática da educação física/ João Batista Freire. - São Paulo: Scipione, 1997. (Pensamento e ação no magistério).

GIL, Antônio Carlos. Como elaborar projetos de pesquisa. 4. ed. São Paulo: Atlas, 2008.

GOLDENBERG, M. A arte de pesquisar. Rio de Janeiro: Record, 1997.

HORA, Dinair Leal. Gestão democrática na escola. 14. ed. Campinas, SP: Papirus, 1994.

KISHIMOTO, T.M. Brinquedos e brincadeiras na educação infantil. Seminário Nacional: Currículo em Movimento Perspectivas Atuais, 2010. Belo Horizonte. Anais. Belo Horizonte: UFMG/MEC, nov. 2010.

LE BOULCH, Jean. O desenvolvimento psicomotor: do nascimento aos 6anos. Trad. Por Ana Guardiola Brizolara. $7^{\mathrm{a}}$ edição. Porto alegre: Artes Médicas,1992. 
LE BOULCH, Jean. Educação psicomotora: psicogenética na idade escolar. Porto Alegre: Artes Médicas, 1987.

LIBÂNEO, José Carlos. Organização e gestão da escola: Teoria e Prática. Goiânia: Ed.Alternativa,2001.

LIBÂNEO, José Carlos. Didática. São Paulo: Cortez, 1994. Coleção magistério $2^{\circ}$ grau. Série formação do professor.

LOPES, Antônia Osima. Relações de Interdependência entre Ensino e Aprendizagem. In: VEIGA, Ilma Passos Alencastro. (Org.). Didática: o ensino e suas relações. 13 ed. Campinas, S. P.: Papirus, 1996. (Coleção Magistério Formação e Trabalho Pedagógico).

LÜCK, Heloísa. Dimensões de gestão escolar e suas competências. Curitiba: Positivo, 2009.

MASETTO, Marcos Tarciso. Didática: a aula como centro. São Paulo: FTD. 1994.

MINAYO, M.C. de S. (Org.) Pesquisa social: teoria, método e criatividade. 22 ed. Rio de Janeiro: Vozes, 2003.

MOLINARI, A.M.P. e Sens, S.M. (2003). A Educação Física e a sua relação com a psicomotricidade. Revista PEC. Vol. 3.

NEGRINE, Airton. Aprendizagem e desenvolvimento infantil: psicomotricidade: alternativas pedagógicas. Porto alegre: Prodil, 1995.

OLIVEIRA, Gislene de Campos. Avaliação psicomotora à luz da psicologia e da psicopedagogia. $4^{\text {a }}$ ed. Petrópolis, RJ: Vozes, 2005. OLIVEIRA, João Ferreira de; MORAES, Karine Nunes de; DOURADO, Luiz Fernandes. Gestão escolar democrática: definições, princípios e mecanismos de implementação. Disponível em <www.letraviva.net/arquivos/2012/anexo-1-gestaoescolar-democratica-dfinicoes-principios--e-mecanismos-deimplmentacao.pdf $>$ Acesso em 01 de novembro de 2019.

ROSA NETO, Francisco. Manual de avaliação motora. Porto Alegre: Artmed Editora, 2002.

SILVA, Alan Marques da. O brincar no contexto escolar: significados das brincadeiras realizadas em aulas de educação física e no recreio -- Campinas, SP: [s.n], 2010.

TISI, L. Educação física e a alfabetização. Rio de Janeiro: Sprint, 2004. 
VINÃO FRAGO, A. Do espaço escolar e da escola como lugar: propostas e questões. In: VINÃO FRAGO, A., ESCOLANO, A. Currículo, espaço e subjetividade: a arquitetura como programa. Rio de Janeiro: DP\&A, 1998, p. 21-57. Tradução de Alfredo VeigaNeto.

VYGOTSKY, L. S. A formação social da mente. São Paulo: Martins Fontes, 1994. 